\title{
CATEGORIZAÇÃO DE USOS MÚLTIPLOS DOS RECURSOS HIDRICOS E PROBLEMAS AMBIENTAIS
}

\section{Categorization of Multiple Uses of Water Resources and Environmental Problems}

Prof $^{0}$ Flávio Rodrigues do Nascimento

Universidade Federal Fluminense - Programa de Pós Graduação em Geografia Instituto de Geociências - s. 506 Campus da Praia Vermelha, CEP: 24210-240 - Niteroi, RJ - Brasil

Tel: (+55 21)26295950 - flaviogeo@bol.com.br

\section{$a_{a} \boldsymbol{a}_{a}$}

\begin{abstract}
Resumo
O trabalho trata sobre a gestão de bacias hidrográficas considerando a degradação da qualidade hídrica, a partir dos usos múltiplos das águas. Neste contexto, as bacias foram consideradas como unidade de gerenciamento integrado dos recursos naturais, diante das alterações na dinâmica ambiental, respostas hidrológicas e nos conflitos por recursos hídricos.
\end{abstract}

Palavras-chave: Bacia hidrográfica, usos múltiplos das águas e conflitos por recursos naturais.

\begin{abstract}
The paper deals about the management of river basin considering the degradation of water quality from the multiple uses of water. In this context, the basins were worked as a unit of integrated management of natural resources in the face of conflicts over natural resources, dynamic changes in environmental and hydrological responses, as well as water quality.
\end{abstract}

Key words: River basin, multiple uses of water and conflicts over natural resources.

\section{Resumen}

El artículo se ocupa de la gestión de las cuencas hidrográficas teniendo en cuenta la degradación de la calidad del agua de los múltiples usos del agua. En este contexto, las cuencas se trabajó como una unidad de gestión integrada de los recursos naturales frente a los conflictos sobre los recursos naturales, los cambios dinámicos en las respuestas ambientales e hidrológicos, así como la calidad del agua.

Palabras clave: la cuenca hidrográfica, usos múltiples del agua y los conflictos por los recursos naturales. 


\section{INTRODUÇÃO}

Com a concepção do ambiente, em grande parte, exterior à existência humana, os recursos hídrCom a concepção do ambiente, em grande parte, exterior à existência humana, os recursos hídricos são apreendidos somente como um recurso natural a ser explorado. Entretanto, há sinais de degradação que ameaçam a segurança hídrica em diversas bacias hidrográficas, no que se refere à escassez da água doce, principalmente associada às vicissitudes climáticas. Isso indica a necessidade de se mudar o padrão de vida de agrupamentos sociais que beira a exaustão.

Em regiões semiaridas, como no Nordeste brasileiro (NEB), estes problemas são agravados por conta de seu quadro geoambiental vulnerável, no qual, principalmente os recursos de água, solo e geobotânico são consumidos e exauridos vorazmente, aumentado assim a susceptibilidade às contingências climáticas, sobretudo termopluviométricas. A redução da biodiversidade, a erosão dos solos e a diminuição espaciotemporal e quali-quantitativa das águas interiores, dos recursos de solo e vegetação, só para citar os mais prejudicados, dão sinais de profunda degradação ambiental na região fisiográfica dos sertões.

Com uma vocação histórica agropastoril desde os primórdios da colonização do Brasil, aliada às condições climáticas desfavoráveis, com as consecutivas e cíclicas secas, há um agravamento dos problemas de degradação ambiental nas paisagens sertanejas, sobretudo nas áreas de bacias hidrográficas semiáridas, em que a sustentabilidade dos recursos naturais é baixa, com base em ecodinâmica instável e níveis de criticidade hídrica comprometedores. Nada obstante, as representações espaciais das bacias hidrográficas na condição de unidades funcionais de planejamento resguardam paisagens, no qual ocorrem interações ambientais, colaborando para que sejam eleitas unidades de planejamento territorial/ambiental adequadas para extrapolar o simples gerenciamento dos recursos hídricos. Uma bacia de drenagem denota características geoambientais, formando unidade natural indissociável e interatuante, podendo facilitar o ordenamento territorial/ambiental, contribuindo para melhor aproveitamento da capacidade de suporte dos recursos naturais.

Ratifique-se que essa unidade é um sistema complexo - dado o número de elementos e variáveis-, interligados por meio de ciclos de transformação, auto-ajuste, dissipação e novamente auto-organização com produção de entropia. As relações mútuas entre seus elementos possibilitam a análise integrada do ambiente, auxiliando em uma acurada avaliação dos aspectos físicos, econômicos e sociais. Neste contexto, considerando a bacia hidrográfica (doravante b.h) na condição de unidade de intervenção e planejamento, o objetivo deste trabalho é destacar os principais usos dos recursos hídricos e dos ambientes hidromórficos nas bacias hidrográficas do Ceará (Figura 1), considerando as alterações na higidez das águas por meio dos pontos potenciais de poluição, mudanças hidrológicas, bem como na redução da resiliência espaciotemporal deste elemento vital.

A bacia como unidade de gerenciamento integrado dos recursos naturais, sobretudo dos mananciais, com fins de seu aproveitamento, coloca os recursos hídricos como elemento indispensável à vida e como insumo às atividades produtivas, pois os usos pelas populações, para irrigação, indústrias, atividades de lazer, dentre outros empregos múltiplos dos recursos hídricos, requer fontes em qualidade e quantidade saudáveis e seguras. Com essa necessidade, o Estado do Ceará, que tem como agravante ao aproveitamento dos recursos naturais a semiaridez foi um dos primeiros da Federação a elaborar plano de recursos hídricos; isso em 1992, por meio da Lei № 11.99.

A partir de então, o quadro hidrográfico do Estado individualiza bacias hidrográficas e conjuntos de bacias, que perfazem o montante de 11 grandes bacias hidrográficas. Dessas, a bacia do rio Jaguaribe $\left(74.621 \mathrm{~km}^{2}\right)$ foi compartimentada em 5 bacias e a bacia Metropolitana $\left(15.085 \mathrm{~km}^{2}\right)$ é formada a partir do agrupamento de 16 bacias independentes. Essas unidades de planejamento, associadas ou não, são: Alto Jaguaribe $\left(24.538 \mathrm{~km}^{2}\right)$, rio Salgado $\left(12.216 \mathrm{~km}^{2}\right)$, Médio Jaguaribe $\left(10.509 \mathrm{~km}^{2}\right)$, rio Banabuiú $\left(19.810 \mathrm{~km}^{2}\right)$ e Baixo Jaguaribe $\left(4.970 \mathrm{~km}^{2}\right)$ que são subdivisões da bacia do Jaguaribe; Parnaíba (composto pelos afluentes Poti, Macambira e o conjunto de sub-bacias Longá-Pirangi $\left(16.901 \mathrm{~km}^{2}\right)$, Curu $\left(9.000 \mathrm{~km}^{2}\right)$, Coreaú $\left(10.500 \mathrm{~km}^{2}\right)$ e Acaraú $\left(14.560 \mathrm{~km}^{2}\right)$ 
complementação a compartimentação hidrográfica cearense. Neste contexto, a bacia do Jaguaribe, compreende $50 \%$ de todo o Estado, drenando áreas ocupadas por $50 \%$ da população estadual, ou seja, drena áreas de municípios com mais de quatro milhões e cinqüenta e três mil habitantes.

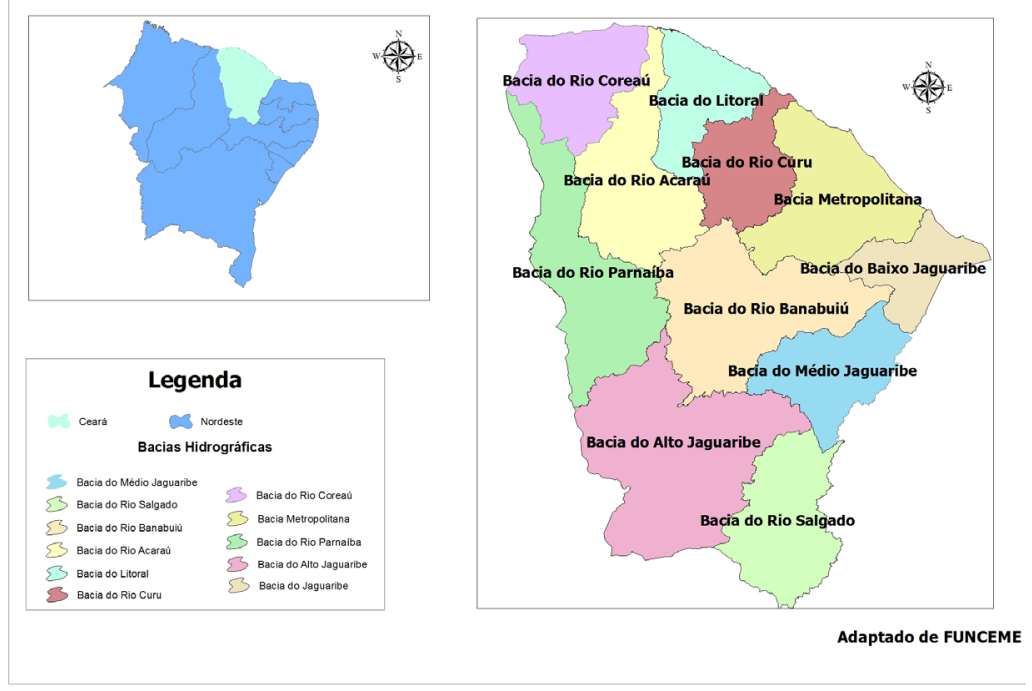

Figura 1 - Bacias Hidrográficas do Ceará. Fonte. COGERH

Tais bacias, (com exceção à bacia do Parnaíba, que pertence a Região Hidrográfica Homônima) pertencem ao grupo de bacias do Atlântico Nordeste Oriental - bacias hidrográficas de rios que deságuam no Atlântico - trecho nordeste, estando limitada ao oeste pela bacia do Parnaíba, ao norte e ao leste pelo Atlântico e ao Sul pela região hidrográfica do São Francisco. Estas apresentam regime fluvial de enchentes durante as chuvas de verão-outono, sendo, a $3^{\mathrm{a}}$. em vazão, com 4,45 $1 / \mathrm{s} / \mathrm{hm}^{2}$ (MMA/SRH, 2004), com vulnerabilidade natural às secas e criticidade de escassez hídrica, o que pode potencializar os conflitos pela água, inferior a $1 / 5$ da vazão específica média nacional que é de 211/s/ $\mathrm{km}^{2}$ (ABRH, 1987 in VIEIRA, 2002).ademais, outra questão de destaque é, segundo o Plano Nacional de Recursos Hídricos, que as bacias do semiárido cearense são parte integrante da Área Especial de Planejamento no contexto da desertificação.

\section{DINÂMICA AMBIENTAL E RESPOSTAS HIDROLÓGICAS EM BACIAS HIDROGRÁFICAS}

Os cursos d'água desempenham funções específicas dentro de cada ecossistema. Os rios, riachos e lagoas propiciam a formação de vegetação ribeirinha, diminuindo a requeima foliar e a caduciofolia através de um feedback de diminuição da evaporação e evapotranspiração e, manuseio da biodiversidade. Além disso, para o diagnóstico do meio físico de bacias hidrográficas, as condições climáticas, a natureza dos terrenos, os aspectos morfopedológicos, os geobotânicos e os de uso/ocupação do solo, influenciam diretamente os recursos hídricos de superfície. O escoamento fluvial e as reservas terrestres implicantes na dinâmica ecossistêmica que formam os geoambientes são, portanto, influenciados, como destaca o Quadro 1, com fatores que necessitam de observação no planejamento dos recursos hídricos.

Como destacou Cunha (1995), mudanças significativas em qualquer desses elementos, podem ocasionar efeitos e/ou impactos a jusante da bacia, bem como nos fluxos energéticos de output ou input de sólidos e substâncias dissolvidas, que em função da escala ou intensidade, dos tipos de leitos e de canais, a morfologia da drenagem pode ser modificada. 
Quadro 1 - Atributos geoambientais incidente sobre os recursos hídricos superficiais

\begin{tabular}{|l|l|}
\hline \multicolumn{1}{|c|}{ Elementos } & \multicolumn{1}{c|}{ Implicações ambientais } \\
\hline Clima & $\begin{array}{l}\text { Distribuição espacial do volume de da freqüência de chuvas, renovação das reservas hídricas, temperaturas e } \\
\text { evapotranspiração Influências sobre o balanço hídrico. }\end{array}$ \\
\hline $\begin{array}{l}\text { Natureza do } \\
\text { terreno e litotipos }\end{array}$ & $\begin{array}{l}\text { Condições geológicas e das formações superficiais, em terrenos impermeáveis, favorecem o adensamento dos cursos } \\
\text { d'água e das depressões lacustres, evaporação. Com zonas permoporosas, a alimentação do lençol freático é favorecida. }\end{array}$ \\
\hline $\begin{array}{l}\text { G e o l o g i a - } \\
\text { Geomorfologia }\end{array}$ & $\begin{array}{l}\text { Processos de escoamento. Características dos perfis longitudinais e transversais dos rios e vales. Velocidade do escoamento } \\
\text { ou retenção, capacidade de incisão para escavar vales e competência das condições de transporte de sedimentos e detritos, } \\
\text { estão associados ao relevo, sua topografia e níveis de declividade. }\end{array}$ \\
\hline $\begin{array}{l}\text { U n i d a d e s } \\
\text { Vegetacionais }\end{array}$ & $\begin{array}{l}\text { Papel protetor das formações superficiais. Uma maior ou menor densidade vegetacional, em seqüência, magnificam ou } \\
\text { atenuam o escoamento superficial nos interflúvios com vegetação densa influenciando o efeito splash e o escoamento. } \\
\text { Menor cobertura vegetacional no meio urbano provoca mudanças microclimáticas. }\end{array}$ \\
\hline $\begin{array}{l}\text { Uso/ocupação da } \\
\text { terra }\end{array}$ & $\begin{array}{l}\text { Efeitos ambientais, diretos e indiretos, no exutório podem ser assinalados: diretamente a retificação, a dragagem do rio } \\
\text { e os barramentos indevidos alteram as condições naturais. Concorrem para as mudanças indiretas o desmatamento, a } \\
\text { impermeabilização de superfícies e as mudanças no uso da terra. Áreas impermeabilizadas favorecem o escoamento. } \\
\text { No meio urbano, a lavagem de superfícies carreia poluentes líquidos e sólidos. No meio rural, os agrotóxicos e o } \\
\text { decapeamento vegetal comprometem a recarga de aqǘferos. Esses fatores em conjunto podem provocar modificações nas } \\
\text { propriedades físicas e estruturais dos solos, na precipitação e temperatura. }\end{array}$ \\
\hline
\end{tabular}

O escoamento fluvial, com alimentação irregular e deficiente, apresenta pequena capacidade de entalhe, grosso modo, em todo o Ceará. Como conseqüências desse entalhe, ocorrem amplitudes altimétricas insignificante entre os interflúvios e os fundos de vales. Cabe exceção aos rios da Bacia do Parnaíba que drenam terrenos sedimentares do Planalto da Ibiapaba, no extremo oeste do Estado. Os rios, em grande parte, apresentam gradientes pouco inclinados e perfis transversais com vertentes planas ou ligeiramente côncavas. Sua rede potamográfica é reflexo direto das condições meso-climáticas. Por isso nas secas os rios "cortam" com exceção dos leitos perenizados dos maiores rios, que somam $1.948 \mathrm{~km}$ de vales úmidos. $\mathrm{O}$ arranjo, em planta, dos exutórios e dos principais tributários no semiárido cristalino, condiz com padrões de drenagem com distribuição espacial do seguinte modo: dendrítica ou arborescente, retangular dendrítica (atribuída aos fenômenos tectônicos), paralela, anastamosada ou cataclinal. Os sistemas hidrográficos em causa apresentam características de drenagem intermitente sazonal exorréica, típica de região semiárida intertropical.

Nos sertões, o padrão de drenagem dendrítica a subdentrítica de textura aberta, é fortemente controlado por fatores estruturais sob efeito de fraturamentos, originando modelo atual de vales com orientação conforme se façam sentir tais efeitos, demando seus níveis de base local, isto é, seus exutórios e tomando-se por referência o nível de base geral - Oceano Atlântico. Não obstante, as chuvas, atingido a superfície, tendem a escoar e a não infiltrarem. Ao escoar, como nos terrenos impermeáveis ou de pouca porosidade dos sertões, alimentam os rios e vão ter com os talvegues. Assim, a hierarquia das drenagens é adensada em ordens de grandeza. Em parte, a água que não escoa e não evapora ou evapotranspira, retém-se no solo ou percola, alimentando o lençol freático conforme as variações faciológicas dos solos.

Nos maciços e cristas residuais a drenagem é dentrítica e/ou subdentrítica fechada, predominantemente pinada, formando canais retilíneos e entrelaçados, de quando em quando, originado meandros com declinação inferior a $5^{\circ}$ de declividade (3-8\%). A depender da altitude e expressão arreal passam a exibir brejos de cimeira em suas vertentes de barlavento. Esse padrão de drenagem colabora com a intensificação da dissecação do relevo em feições colinosas convexas.

Nas porções pré-litorais a drenagem tem canais paralelos nos tabuleiros - com declínio discreto demandando os níveis de base, conforme esquema retromencionado -, e anastomosada na planície fluviomarinha (litoral). Sendo que nas coberturas sedimentares da Ibiapaba a drenagem é cataclinal, com leve caimento topográfico para Nordeste. Ocorre aí, garganta epigênica/boqueirão pela superimposição do rio Poti demandando seu exutório, Parnaíba. Na Chapada do Araripe ocorrem os brejos de encostas e pés-de-serras, em razão de ressurgências, formando espraiamentos de 
sucessivos vales nos sopés dos contrafortes da Chapada, ao tempo que denunciam a exigüidade ou mesmo inexistência de rios no platô. Por seu turno, a Chapada do Apodi é côngere ao Araripe neste contexto, de certo que forma micro-bacias, a exemplo da Malhada Vermelha no Município de Tabuleiro do Norte, como tributárias dos rios Quixerê e Juaguaribe. Em síntese, na Ibiapaba ocorrem rios obsequêntes, a exemplo do Ipussaba e outros no Parque Nacional de Ubajara, bem como aqueles entre os municípios de Graça e Ibiapina, formando belas quedas d'água. Ao passo que no Araripe e Apodi os rios não formam rios conseqüentes e nem obsequêntes, originando rios subseqüentes alimentandos por nascentes, em níveis topográficos mais rebaixados.

Os rios do Nordeste, em determinadas épocas do ano, atingem o mar tratando-se de um dos fatores de originalidade dos sistemas hidrográficos e hidrológicos regionais, que ao contrário de outras regiões semiaridas do mundo, em que as drenagens convergem para depressões fechadas, os rios dessa região vão ter com o Atlântico. Por isto, no semiárido em geral, e no Ceará em Particular, os rios são de caráter intermitente, com drenagem exorréica, que em grande escala não permite a formação de solos originalmente salinos, principalmente nas vertentes e interflúvios. Os sais dissolvidos da litologia cristalina, predominante na meso-estrutura, e aqueles provenientes das chuvas carregadas de águas evaporadas do oceano, vão ter com o nível de base após arraste pelo fluxo hídrico das torrentes. Pela capacidade de erosão, transporte e deposição, ademais, os rios são os principais agentes transformadores da paisagem, modelando o relevo. Neste contexto, processos fluviais como processos aluviais, compreendendo a erosão, transporte e sedimentação em leques aluviais e rios, ajudam a explicar a ocorrência de minérios como o urânio fosfatado a despeito das Sub-bacias do rio Groaíras $\left(2.917,3 \mathrm{~km}^{2}\right)$ em Santa Quitéria, contribuinte do rio Acaraú, com a mina Itataia.

Em termos qualitativos, as características da rede de drenagem, segundo Oliveria e Ferreira (2001), podem ser definidas através de particularidades chamadas características fundamentais ou qualitativas (Quadro 2). Observamos, dentre outros aspectos, relevo acidentado pela assimetria das vertentes, influências tectônicas-rupturais na orientação da drenagem e forte integração dos canais de drenagem, colaborando para um desenho, em planta, da rede de drenagem de muitas ramificações na maioria das bacias hidrográficas do Ceará.

Os elementos qualitativos e as características naturais dos vales fluviais, demonstrados, no próximo quadro, são importantes no gerenciamento de recursos hídricos. Todavia, uma caracterização hidrológica mais rica passa por apreciação genérica da geomorfologia fluvial regional, no que se refere às características naturais dos rios e canais. Neste sentido, além dos tipos de padrão de drenagem, escoamento e sua gênese, os vales fluviais podem ser entendidos à luz dos tipos de leitos e dos tipos de canais. De vez que cada uma dessas fisionomias apresenta dinâmica peculiar das águas correntes, associadas à geometria hidráulica específica, originada pelos processos erosivos, de transporte hidrossedimentológico e agradacionais. Desta feita, o Quadro 3 generaliza as características naturais dos vales fluviais no Ceará.

No que se refere às potencialidades hidrogeológicas, reservatórios subterrâneos diversos, desde zonas fraturadas ou de rochas intemperizadas do substrato geológico Pré-Cambriano até depósitos quaternários aluviais, ocorrem nas depressões sertanejas. Os depósitos de aluviões apresentam dimensões variadas, geralmente reduzidas, contendo volumes de água acumulados que podem remontar às origens de suas formações geológicas. Sua disponibilidade pode ter potencial hídrico ainda não usado pelos homens, podendo as reservas ser acrescidas, se alguma demanda socioeconômica assim exigir. A capacidade de armazenamento d'água subterrânea é fornecida por arranjos estruturais, localizados nos contatos geológicos, por falhas e no manto de alteração. As fissuras e fraturas, como porosidade secundária, no qual a água circula, apresenta condutibilidade hidráulica não com base em porosidade primária das rochas, como no caso de aqüíferos clásticos, mas pelos efeitos dos componentes estruturais alimentados por precipitação atmosférica, rede hidrográfica e as aluviões. Em regra, as águas subterrâneas do domínio cristalino são limitadas. A vazão média em poços tubulares é ínfima, da ordem de $5 \mathrm{~m}^{3} / \mathrm{h}$, e salinidade média da ordem de $2 \mathrm{mil} \mathrm{mg/L,} \mathrm{o}$ 
que pode comprometer sua potabilidade. Dada a falta de fiscalização das atividades de perfuração e uso de poços, estima-se que no Nordeste existem aproximadamente 50 mil, e pouco mais de 20 mil estão em operação por motivos técnicos e/ou políticos (REBOUÇAS, 2002). Na região hidrográfica Atlântico nordeste oriental, essa situação pode ser agravadas pela baixa vazão média com $2 \mathrm{~m}^{3} / \mathrm{h}$.

Quadro 2 - Características qualitativas da bacia de drenagem do Acaraú

\begin{tabular}{|c|c|c|}
\hline $\begin{array}{c}\text { Características } \\
\text { Qualitativas }\end{array}$ & Descrição & Respostas qualitativas da rede de drenagem \\
\hline Grau de integração & $\begin{array}{l}\text { Caminho dos canais entre dois pontos. Quanto } \\
\text { mais curto o caminho maior a integração }\end{array}$ & $\begin{array}{l}\text { Não integrada - os canais não se ligam ( ) } \\
\text { Pouco integrada - poucos canais se ligam( ) } \\
\text { Integrada - todos os canis se ligam ( X ) }\end{array}$ \\
\hline Grau de uniformização & $\begin{array}{l}\text { Repetição das formas da rede de drenagem num } \\
\text { curto espaço }\end{array}$ & $\begin{array}{l}\text { Não uniforme }(\text { ) } \\
\text { Pouco uniforme }(\text { ) } \\
\text { Uniforme }(\mathbf{X})\end{array}$ \\
\hline Orientação & Direção predominante dos drenos & $\begin{array}{l}\text { Não orientada ( ) } \\
\text { Pouco orientada ( ) } \\
\text { Fortemente orientada }(\mathbf{X})\end{array}$ \\
\hline Grau de controle & Fatores que alteram o sentido da drenagem & $\begin{array}{l}\text { Não controlada }(\text { ) } \\
\text { Controlada }(\mathbf{X}) \\
\text { Altamente controlada }()\end{array}$ \\
\hline Angularidade & Mudança na direção dos leitos & $\begin{array}{l}\text { Baixa }(\mathbf{X}) \\
\text { Média }() \\
\text { Alta angularidade ( ) }\end{array}$ \\
\hline Ângulos de juntura & $\begin{array}{l}\text { Ângulo formado na foz de um tributário com seu } \\
\text { receptor }\end{array}$ & $\begin{array}{l}\text { Reto (X) } \\
\text { Agudo ( ) } \\
\text { Muito Agudo ( ) }\end{array}$ \\
\hline Simetria das vertentes & $\begin{array}{l}\text { Correspondência em grandeza, forma e } \\
\text { orientação relativa }\end{array}$ & $\begin{array}{l}\text { Simétrica ( ) } \\
\text { Assimétrica ( X ) }\end{array}$ \\
\hline
\end{tabular}

Fonte: Adaptado com base em Oliveria e Ferreira (2001)

Nas áreas pré-litorâneas, costeiras, sedimentares e aluviais estão os maiores aportes de águas subterrâneas, mas exigindo rigores técnicos em suas explotações, assim como usos mais coletivos deste recurso valioso tão valioso.

Com índices de evaporação críticos na região favorecedores de balanço hídrico deficitário, as águas subterrâneas se encontram mais bem protegidas, com uma parcela de perda hídrica consideravelmente menor do que aquela perdida por mananciais de superfície. Portanto, comportam-se como reservas hídricas que podem ser importantes principalmente durante as estiagens, para o aproveitamento prioritário humano, dessedentação de animais e outros. Por isso, desde já, as demandas para tal fim devem ser garantidas, em qualquer cenário considerável, conservando e distribuindo equilibradamente aportes deste recurso vital, em quantidades e qualidades mínimas, preferencialmente aos usos mais nobres da água. 
Quadro 3 - Características naturais dos vales fluviais

\begin{tabular}{|c|c|c|c|c|c|}
\hline \multirow[b]{2}{*}{ Bacias de drenagem } & \multirow[b]{2}{*}{ Tipo de leito } & \multirow[b]{2}{*}{ Tipo de canais } & \multicolumn{3}{|c|}{ Tipo de padrão de drenagem } \\
\hline & & & Escoamento & Gênese & Geometria \\
\hline Bacias & $\begin{array}{l}\text { Leito menor, de } \\
\text { varzante, maior } \\
\text { excep-cional }\end{array}$ & $\begin{array}{l}\text { Meandrante, } \\
\text { anastomosado } \\
\text { na planície } \\
\text { fluviomarinha }\end{array}$ & Exorréica & $\begin{array}{l}\text { Conseqüente, } \\
\text { obseqüente, } \\
\text { subseqüente. }\end{array}$ & $\begin{array}{l}\text { Dendrítica e sub-dendrítica } \\
\text { (médio e alto curso), paralelo } \\
\text { (baixo curso) }\end{array}$ \\
\hline $\begin{array}{l}\text { Prinicipais Sub- } \\
\text { bacias }\end{array}$ & $\begin{array}{l}\text { Leitos menor, de } \\
\text { varzante, e maior } \\
\text { excepcional }\end{array}$ & $\begin{array}{l}\text { Retilíneo parealelo } \\
\text { e meandrante } \\
\text { irregular }\end{array}$ & Endorréica & $\begin{array}{l}\text { Conseqüente, } \\
\text { obseqüente, } \\
\text { subseqüente } \\
\text { inseqüente }\end{array}$ & Dendrítica, Sub-dendrítica. \\
\hline
\end{tabular}

\section{GESTÃO DE BACIAS, DEMANDAS E USOS}

Pela necessidade que representa a água - como insumo produtivo, composição da paisagem, interferência em processos biogeoquímicos, para vida humana etc -, os recursos hídricos são utilizados para múltiplos fins. Ocorre desde a retirada de água das coleções hídricas, promovendo perda entre derivação e o que retorna ao corpo hídrico, alterando sua quantidade, e perdas de qualidade por causa de finalidades subseqüentes, a usos não consuntivos, quando não se tem necessidade de retirar as águas de suas coleções, isto é, o uso in situ. Nesse espectro, a Lei de Recursos Hídricos do Ceará ( $n^{\circ} 11.99$, de 24/07/1992) prevê alguns instrumentos legais, como outorga de direito de uso dos recursos hídricos, o licenciamento para obras hídricas e a cobrança pelo uso da água bruta. No prisma de recursos hídricos e convivência com o fenômeno da seca e combate à desertificação, ao passo que alguns dos principais problemas do semiárido brasileiro cabem referenciar a definição e caracterização das principais funções, com as respectivas subfunções em termos da gestão, oferta e conservação das águas das bacias hidrográficas cearenses.

Os usos não consuntivos não demandam padrões rígidos de qualidade, embora não se possa dispensar um mínimo de qualidade e de características estéticas, sobretudo em relação à sua função paisagística. Assim, estão condicionados a recreação e lazer, transporte, navegação e diluição de dejetos. Ao passo que, isso, os usos consuntivos exigem melhores padrões de qualidade da água em virtude de englobarem o abastecimento público e industrial e agroindustrial (instalação de tanques para carcinicultura, por exemplo), agropólos (Baixo Jaguaribe, Baixo Acaraú, Cariri, Centro Sul, Ibiapaba e Metropolitano), dessedentação de animais e o mais nobre dos usos da água, o consumo/ abastecimento humano.

Dentre as demandas por água observadas em Heller e Casseb (1995) no plano nacional, E Nascimento (2006 ) em relação a Região Nordeste do Brasil, algumas podem ser constadas como ocorrentes nas Bacias cearenses, no abastecimento das populações, setores produtivos e em outras demandas de usos, variando desde os mais nobres aos menos urgentes. Anotamos que, quanto maiores os núcleos urbanos e a atividades agrícolas, mais intensos são os consumos d'água. Assim, os núcleos urbanos das cidades e as atividades agroindustriais demandam os maiores aportes desses recursos e, conseqüentemente, ocosionam o maior volume de efluentes, entre eles: esgotos domésticos e industriais, graxas, águas compostas por defensivos químicos, rações e antibióticos para aqüicultura, partículas em suspensão, dentre outros poluentes, quais sejam:

. Público - rega de logradouros, parques e jardins, chafarizes, poços, edifícios públicos, piscinas públicas e recreação, escolas, hospitais, mercado público, pesca, paisagismo dentre outros;

. Doméstico - higiene corporal, descarga de sanitários, preparo de alimentos, bebidas, lavagem de roupa e automotores, rega de jardins e quintal, limpeza em geral etc;

. Comercial - restaurantes, bares e lanchonetes, lojas, postos de gasolina, frigoríficos, escolas, salões de beleza, dentre outros; 
. Agrícola e pecuária - irrigação e agropólos, lavagem de currais, instalações de tanques para clube "pesque-e-pague", abastecimento de açudes;

. Industrial/agroindustrial - água como matéria-prima, consumida no processo, utilizada para resfriamento e lavagem, necessária para a instalação de sanitários, refeitórios, enchimento de tanques para carcinicultura.

. Especial - combates a incêndios, instalações desportivas, estações rodoviárias e aeroviárias, diluição de dejetos etc.

Quadro 4 - Funções do sistema da gestão de água e demais sistemas, consideradas no Plano de Recursos Hídricos do Ceará em 1992

\begin{tabular}{||c|c||l||}
\hline \multicolumn{2}{|c||}{ Gestão } & Planejamento; administração; regulamentação \\
\hline \hline \multirow{2}{*}{$\mathrm{U}$} & Oferta & Nucleação artificial; represamento; poços; cisternas \\
\cline { 2 - 4 } o & Não Consuntivo & Geração hidrelétrica, navegação fluvial, lazer, pesca e piscicultura extensiva, assimilação de esgotos. \\
\hline \multirow{2}{*}{ Preservação } & $\begin{array}{l}\text { Lazer, turismo, manutenção do ciclo hidrológico e higidez hídrica, recarga de aqüíferos, manutenção } \\
\text { microclimática e da biodiversidade. }\end{array}$ \\
\hline \multicolumn{2}{|c|}{ Complementares } & Ciência e tecnologia, meio ambiente, planejamento global, incentivos econômicos, defesa civil abastecimento industrial, aqüicultura, abastecimento urbano. \\
\hline
\end{tabular}

Fonte: Adaptado de Campos (2002).

Não podemos deixar de mencionar as demandas pelas atividades de engenharia com barragens (açudagem) e perenização de seções dos rios, além daquelas voltadas ao turismo, ocupações lúdicas e de balneabilidade, pesca, piscicultura, maricultura, abastecimento animal, abertura de poços, principalmente nos sertões, e as necessidades de água da própria natureza, como a recarga de aqüíferos. Nestes processos, ocorrem perdas na adução, no tratamento, na rede de distribuição e nos próprios domicílios, além dos eventuais desperdícios nos pontos de tratamento.

A pesca, recreação e contato primário, dessedentação de animais, diluição de dejetos, abastecimento público e irrigação ou uso residencial estão entre as principais modalidades de exploração dos recursos hídricos. Vale ressaltar que os corpos d'água se constituem como grande atrativo cênico, em que se praticam esportes náuticos, e que propiciam a preservação da comunidade aquática. Os córregos, riachos e açudes são usados para higiene, lavagem de roupas, irrigação de lavouras de subsistência e para o banho das comunidades carentes no meio rural, ao passo que o meio urbano os poluem com resíduos sólidos e dejetos. A demanda por água é intensificada nos meses de agosto e setembro, exatamente quando a evaporação é mais elevada, acarretando a diminuição da quantidade e qualidade hídrica, piorando as condições de vida destas comunidades e aumentando os conflitos por água.

Áreas de colúvios, perímetros irrigados, margens ribeirinhas, faixa de periferia das represas, serras com seus brejos e as áreas de chapadas, apresentam melhores condições edafoclimáticas no cerne dos sertões secos como áreas de exceção. A rigor, os usos dos recursos hídricos podem ser diferenciados ao longo do espaço conforme as unidades geoambientais, preferencialmente destacando alguns ambientes hidromórficos, que se configuram como se fossem oásis dos desertos quentes, atenuam as contingências termopluviométricas dos sertões semiáridos.

Nos litorais, as planícies fluviomarinhas possibilitam a pesca artesanal, a maricultura e o turismo, bem como o desenvolvimento de estudos científicos e a conservação compulsória. Entretanto, estes geoambientes sofrem problemas de degradação pela mobilização artificial das dunas, desmatamentos, urbanização e, principalmente, pelo definhamento de fontes de água, a montante nas bacias. Com o desenvolvimento da carcinicultura, a demanda por águas estuarinas é crescente, 
o que pode diminuir o fluxo fluvial das camboas, interferindo e desregulando a compensação da salinidade do estuário. As áreas que outrora foram salinas, naturalmente recolonizadas por apicuns (vegetação halofítica herbácea), quando o mangue não tenha se regenerado, constituem-se como áreas alagáveis e descampadas próximas à barra dos exutórios, que são ocupadas pela pecuária extensiva e extração de crustáceos, além de algumas representarem zona de litígio e conflitos entre comunidade tradicional e carcinicultores, com destaque as áreas potamais do oeste cearense - comunidade de Curral Velho, por exemplo, na planície fluviomarinha do Acaraú.

As várzeas, típicas das planícies fluviais, inundadas somente em tempos de chuvas expressivas, estão presentes em todos os setores das Bacias - com exceção das serras cristalinas residuais e inselbergs -, comumente formando ecotónos com outros ambientes. Embora degradadas, são aproveitadas com a agricultura de vazantes e agropecuária extensiva. Do mesmo modo, em porções mais deprimidas da Depressão Sertaneja, distribuem-se, dispersamente, pelos sertões as áreas de acumulação inundáveis (baixios), que acumulam água ao final do período chuvoso, podendo originar pequenas lagoas, oferecendo-se como fontes opcionais para as comunidades.

As áreas de segurança dos açudes, ou seja, suas margens forjam ambientes hidromórficos. Com o período de escassez de chuvas e redução significativa de seu uso ótimo, como também durante a sangria desses reservatórios, condições edafológicas de maior umidade são atrativas a mais para o cultivo de policulturas, por pequenos proprietários e até mesmo por grandes proprietários - que têm áreas de açudes públicos em suas terras. Em todos os casos, os riscos de contaminação por fertilizantes defensivos químicos e transporte de sedimentos são potencializados para o interior das coleções hídricas, podendo provocar eutrofização, principalmente os maiores açudes do Estado, tais como Castanhão (Médio Jaguaribe) e Orós (Alto Jaguaribe), Banabuiú (Bacia de mesmo nome), Pentecoste (Bacia do Curu), Edson Queiroz, Acaraú Mirim e Varjota (Acaraú), Jaburu I (Bacia do Parnaíba) além dos outros mais de 120 monitorados pela Companhia de Gestão de Recursos Hídricos do Ceará.

Em meio às precárias condições de saneamento, algumas áreas de acumulações inundáveis ou mesmo lagoas ou planícies fluviolacustres são contaminadas com águas servidas em alguns $\mathrm{Mu}-$ nicípios, a exemplo de Mucambo, Sobral, Groaíras, Santana do Acaraú e Cruz (Bacia do Acaraú), Granja e Camocim (Bacia do Coreaú), Mobamça e Milhã (Bacia do Banabuiú), Choró e Itapiúna (Sub-bacia do Choró/Bacia Metropolitana) formando as popularmente denominadas "capineiras". Constituem formas alternativas para criação de pastos à alimentação de gado bovino por pequenos criadores.

Os açudes, mesmo com todos os problemas, sobretudo os públicos, as passagens molhadas - pequenos barramentos que retêm ínfimos volumes d'água temporariamente -, e as cisternas de placas são alternativas para o acesso à água das comunidades mais carentes. Cabe dizer que os ambientes hidromórficos quanto às formas de uso dos recursos hídricos, em conjunto, ajudam a compor os arranjos de uso/ocupação agrossocioeconômica (campos cultivados com desenvolvimento agrossilvopastoril), que de per si, demanda estudos analíticos aprofundados. Entrementes, é triste constatar a contaminação dos recursos hídricos e as possíveis mudanças hidrológicas.

Convém lembrar que um forte debate hoje sobre o abastecimento de água no Nordeste, mormente nos Estados setentrionais do Ceará, Rio Grande do Norte, Paraíba e Pernambuco, concentra-se na conveniência, ou não, de promover a transposição no São Francisco. Essa questão remonta à metade do século XIX (1847), porém, até os anos de 1980, era um projeto tido como inviável em razão da falta de energia para o bombeamento demandado. Nesse período, dentre outras propostas, foi elaborado o primeiro projeto de transposição para vazão de $300 \mathrm{~mm}^{3} / \mathrm{s}$. O projeto atual prevê vazão média de $64 \mathrm{~m}^{3} / \mathrm{s}$, para abastecimento rural, consumo humano e usos agrícolas difusos, abastecimento urbano e industrial e estímulo ao desenvolvimento de agricultura irrigada de alto valor agregado. Com isto, segundo o Governo Federal, as áreas irrigadas seriam ampliadas, a agroindústria e a indústria minero-metalúrgica seriam dinamizadas e outros serviços modernos 
restariam fortalecidos. Tecnicamente, esse projeto propõe uma sucessão de canais, túneis, reservatórios e aquedutos que terão origem em duas2 tomadas d'água a jusante da barragem Sobradinho. Com ramificações de aproximadamente $700 \mathrm{~km}$ de extensão, há 2 (dois) conjuntos de eixos, com duas fontes de captações d'água: uma tomada para o eixo norte, com instalação nas proximidades de Cabrobó-PE; outra para o eixo leste, saindo do reservatório de Itaparica; prevê dois eixos, tomando-se por base Sobradinho, partindo para oeste (Piauí) e para Sul (Bahia, indo para Sergipe através do rio Vaza Barris).

Apesar de pequena proporção de vazão média do rio nos pontos de derivação, além da complexidade inerente de um projeto de transposição em termos técnicos e político, são conflitantes outros interesses dos 10 Estados envolvidos. Ganham, portanto, efervescência temas envoltos em: negociação e solução de conflitos, abordagens econômico-financeiras, propostas para elaboração do projeto, aspectos institucionais, questões ambientais e sociais.

Para o Ceará, a agroindústria para exportação, a siderurgia no Porto do Pecém e a Região Metropolitana de Fortaleza (RMF) serão os beneficiários diretos da transposição no contexto da articulação com o Projeto Cinturão das Águas no Ceará. Este terá como coletor o seguinte sistema: captação em Cabrobó (PE) - açude Atalho, no rio Cuncas; em Brejo Santo, Ceará - rio Salgado e Jaguaribe, até o açude Castanhão, e como um dos distribuidores, o Canal da Integração. Contudo, desses setores econômicos e porções do território beneficiado, a transposição mostra-se seletiva e excludente. Privilegia o grande capital e a RMF, em detrimento dos pequenos produtores, pequenas e médias cidades sertanejas.

Isto em face de uma perspectiva de reestruturação produtiva, com implicações territoriais, engendradas pelos Governos em suas três esferas administrativas, aliadas ao capital agroindustrial, petroquímico e siderúrgico, por exemplo. Decorre daí uma série de conflitos territoriais, onde o elemento água assume conotação importante. Ao tempo que as territorialidades, neste contexto, urgem enquanto estratégias dos agentes envolvidos na questão, em face de conflitos territoriais ambientais. A saber:

Pequenos produtores x agroindústria,

. Preservação x atividades produtivas, especialmente agroindústrias.

. Urbanização x usos múltiplos dos recursos hídricos.

Todavia, para o momento convém ao menos levantamos algumas hipóteses sobre a questão posta, as quais necessitariam de comprovação em pesquisas futuras:

a. Até que ponto o Canal da integração e o Açude Castanhão, no contexto do Cinturão das Águas, se comportam como principais objetivos de suporte à reestruturação produtiva e territorial na concepção política e prática do Governo do Estado?

b. Estes equipamentos hídricos estão no cerne da questão considerando os deslocamentos de produtores rurais, os conflitos por recursos naturais, sobretudo os hídricos?

c. A migração compulsória e os deslocamentos de produtores rurais, aliado aos conflitos por recursos naturais, sobretudo os hídricos, estão relacionados ao que poderíamos chamar de hidroterritórios?

Até que ponto, não se poderia ventilar em tratar processos de desterritorialização e reterritorialização a partir das nuances que envolvem o Cinturão das Águas no Ceará, com drásticos problemas ambientais, socioeconômicos e culturais para os pequenos produtores rurais?

Além do mais, pouco se sabe a respeito dos impactos sobre a desertificação, além dos riscos de 
salinização por irrigação e o possível agravamento de conflitos pela terra e usos d'água. Apenas as sub-bacias do Médio e Baixo Jaguaribe, em articulação com bacias da Região Metropolitana estão inclusas no projeto, não havendo preocupação neste sentido em relação às demais bacias do Estado. No mais, essa bacia poderá sofrer como de resto outras regiões do Ceará, efeitos proeminentes da não-tecnificação do território e alocação de recursos em áreas não consideradas estratégicas para o setor empresarial e industrial, conforme perspectiva estadual.

\section{ALTERAÇÕES NA HIGIDEZ DAS ÁGUAS: PONTOS DE POLUIÇÃO, MUDANÇAS HIDROLÓGICAS E DIMINUIÇÃO DA RESILIÊNCIA ESPACIOTEMPORAL}

A água, recurso natural renovável, porém exaurível, é impactada por ações socioeconômicas que lhe conferem degradabilidade, reduzindo-lhe a higidez utilizável em intervalos espaciotemporais freqüentemente mais curtos. As formas de utilização da água, ao contrário do que ocorre com a maioria de outros recursos naturais que desaparecem com o uso, produzem modificações sensíveis em seus aspectos quali-quantitativos. Desta forma, a contaminação dos recursos hídricos compromete a resiliência das águas e a geodinâmica das Bacias, competido para agravar o estado de conservação dos recursos naturais.

Os principais tipos de poluição (pontuais ou difusos) estão vinculados a diversos fatores e vetores, dentre eles a dificuldade de acesso tecnológico, o baixo nível de consciência humana e a falta ou carência de investimentos em saneamento ambiental. Dentre os principais citam-se:

. Esgotos domésticos e comerciais - principais introdutores de matéria orgânica e demais compostos biodegradáveis e/ou não-biodegradáveis nos ecossistemas aquáticos contribuem para o a depleção de $\mathrm{O} 2$ e favorecem processos de eutrofização;

. Águas servidas dos trabalhos agropecuários e de matadouros - os fertilizantes e defensivos agrícolas, em geral, podem ser transportados pelas águas da chuva, favorecendo processos de eutrofização, ou se infiltrarem no subsolo, acumulando nitratos e nitritos nas águas, deletérios à saúde humana. A lavagem de matadouros e o estouro de fossas sépticas contribuem para a poluição por matéria orgânica, reduzindo a concentração de oxigênio dissolvido nos corpos receptores;

. Os despejos industriais/agroindustrias e hospitalares - principalmente ocasionados pelas olarias e indústrias, especialmente, de transformação espalhadas pelas Bacias, quando são lançados a céu aberto, incorporam-se à rede de drenagem quando não são diretamente despejados in natura nas coleções d'água. Podem variar conforme o porte da indústria, em composição e volume. Os perímetros irrigados podem contaminar as águas subterrâneas com sais, exemplo do Tabuleiro de Russas, Chapada do Apodi, Icó Lima Campos no Vale do Jaguaribe, Curu-Paraipaba no vale do rio Curu, Varjota e Baixo Acaraú, no Vale homônimo. A despesca da carcinicultura lança aos recursos hídricos grandes cargas de poluentes, incluindo restos de ração e antibióticos, que podem provocar aumento da turbidez, depleção de $\mathrm{O} 2$, comprometimento da biota e eutrofização. As águas servidas dos hospitais são de alto risco à saúde pública, pois são ricas em substâncias patogênicas que vão ter com as drenagens, quase sempre sem tratamento.

Convém registrar que na RMF, em Sobral e no Crajubar (Crato-Joazeiro-Barbalha) ocorrem as maiores concentrações industriais de todo o Estado, e por conseqüência, os maiores problemas em relação às águas servidas de suas atividades. Nada obstante, os agropólos se destacam como os maiores utilizadores do produto água, merecendo igualmente atenção especial sobre sanitaridade ambiental e conflitos por utilização dos recursos naturais.

- Deficiência na coleta sistemática de lixo e falta de aterros sanitários - parte do lixo produzido é depositada a céu aberto - por vezes, próximo aos veios fluviais e terrenos mais permopo- 
rosos. A disposição de lixo nos terraços mais baixos facilita a ação do chorume, induzindo o escoamento e/ou percolação de substâncias poluidoras. Um subproduto altamente tóxico que é comum na produção das cerâmicas e olarias é o cádmio. Em todo o Ceará a exigüidade de aterros sanitários, menos de uma dezena, é lastimável. A RMF dispõe de aterros sanitários em Caucaia, Fortaleza (em processo desativação) e Aquiraz. Em toda região norte, para se ter uma idéia, o aterro de Sobral é o único, em consórcio com outros Municípios da Meruoca; embora sua localização seja na vertente ocidental da Serra do Jordão.

. Águas urbanas de escoamento superficial - representam foco de poluição hídrica, no momento em que são transportados detritos e volumes poluentes de toda sorte pelas águas e ventos.

Segundo Campos (2002), o ambiente é contaminando com substâncias orgânicas, inorgânicas e tóxicas (metais pesados, ácidos, pesticidas etc), sais não tóxico (cloreto de sódio e sulfato de potássio) e substâncias antiestéticas. Em razão dos problemas sanitários envolvendo esses poluentes, às temperaturas elevadas e a diminuição da quantidade das coleções hídricas no segundo semestre de cada ano - associando-se à deposição de dejetos e aos hábitos da população - as chances de surgimento de enfermidades veiculadas pela água exigem maiores cuidados pelas autoridades competentes. $\mathrm{O}$ maior problema sanitário diz respeito às doenças provocadas pelos esgotos. Quando as águas em quantidade são insuficientes para higiene pessoal e/ou estão contaminadas podem causar doenças. Certamente, as fontes de poluição podem provocar o aumento de incidência de doenças de veiculação hídrica, - como malária, mal-de-Chagas, febre amarela, febre tifóide, tracoma, escabiose, lepra, conjuntivite, dermatites dentre outras -, tencionando a relação estreita entre água e saúde pública. Pode, ainda, elevar o teor de matéria orgânica nos lençóis subterrâneos e coleções d'água de superfície, tornando a qualidade da água imprópria para usos múltiplos.

É importante lembrar que, além dos problemas de saúde humana, a contaminação das águas afeta a qualidade e a diversidade biológica, ao passo que as atividades produtivas ficam comprometidas. Por isso é que a gestão dos recursos naturais, nesse caso preferencial, os hídricos, é urgente e - os Comitês de bacias têm papel preponderante para integrar institucionalmente os diversos interesses, pois seus poderes consultivos e deliberativos, de instância mais importante de participação e integração do planejamento e das ações relacionais aos recursos hídricos, são imprescindíveis na mediação dos conflitos, advindos das políticas econômicas e atividades sociais - uso e ocupação do solo (estrutura fundiária, urbanização etc) demografia, industrialização, impactos ambientais, macroprojetos etc. obviamente, resguardam as devidas proporções de atuações e responsabilidades das três esferas governamentais.

A título de exemplificação, foram visitados diversos pontos potenciais de poluição em 25 municípios na Bacia do rio Acaraú, no centro-norte cearense, considerando também as Estações de Tratamento de Água (ETA's) e Estações de Tratamento de. Esgoto (ETE's). Em maioria, as estações não apresentam condições ideais de funcionamento, cabendo às ETE's os maiores problemas. Neste sentido, é mister melhorá-las, porque, conforme Campos (2002), elas representam sistemas de tratamento econômico e têm potencial para produzir efluentes isentos de helmintos, protozoários, bactérias e vírus, possíveis de uso para irrigação.

O processo de desenvolvimento deflagrado, nada obstante, provoca elevação na demanda pelos recursos naturais, sem proporcionalmente sequer promover melhoria na qualidade de vida da população residente. As atividades regionais desenvolvidas modificam os usos múltiplos da água e seus aspectos espaciotemporais, desfigurando as paisagens - amalgama dos componentes do quadro biofísico das Bacias-, reduzindo sua biodiversidade. Tendo como referência a complexidade que são as bacias hidrográficas, seus canais fluviais e o escoamento das águas, podemos dizer que ocorrem formas diversificadas e desregradas de ocupação do solo em seus domínios, em que emergem conflitos e impactos de variadas etiologias. Exemplo disto é o que se verifica com as tipologias de uso e ocupação da terra. 
Conforme o uso e ocupação do solo podem ocorrer impactos ambientais diretos e indiretos nos exutórios das bacias. Sobre os impactos diretos, assinalamos: retificação, dragagem do rio e barramentos indevidos. Por outro lado, no que diz respeitos aos impactos indiretos, é possível encontrar: desmatamento, impermeabilização de superfícies e mudanças no uso da terra; e, até mesmo ocorrer modificações nas propriedades físicas e estruturais dos solos, na precipitação e temperatura.

A depender das obras de engenharia e das sucessivas retificações dos rios, os impactos sobre b.h's, principalmente a montante de reservatórios, no próprio reservatório e em sua periferia, bem como a jusante da barragem podem ser de várias etiologias: hidrológicos, microclimáticos, geomorfológicos e bióticos (CUNHA, 1995). Em especial, a canalização, que pode ser observada nos perímetros irrigados e em alguns centros urbanos como Russas (Vale do Jaguaribe) e Crato (Vale do Salgado), Pacujá, Morrinhos e principalmente em Sobral (Vale do Acaraú), representam obras de engenharia desenvolvidas no sistema fluvial, envolvendo direta modificação da calha do rio e ocasionando impactos diretos no canal e na planície de inundação. O sinergismo das atividades socioeconômicas altera o equilíbrio dos canais, promovendo mudanças no ciclo hidrológico e nos processos fluviais. Ademais, sobre as características e problemas de canais retificados, pode ser produzido um "arquivo de informações", para perspectivas de análises. Como exemplo, o Quadro 05 sumaria esses aspectos, como reflexo das atividades socioeconômicas e da dinâmica biofísica no riacho Mucambinho em Sobral, margem esquerda do Acaraú e do rio Granjeiro, na cidade do Crato, Bacia do Salgado - no extremo sul do Estado, bem como no rio Maranguapinho, na RMF, um dos mais alterados do Estado, com poluição e retificações de canais.

Interferências humanas na geomorfologia fluvial afetam a bacia e seus canais constituintes, por isto o homem pode ser considerado um agente geomorfológico influenciador, por exemplo, da morfodinâmica. Os usos múltiplos d'água, com usos consultivos e não consultivos nas atividades rurais e urbanas alteram as condições naturais dos rios em foco, principalmente da sua dinâmica fluvial, com conseqüências de causa e efeito, podendo provocar impactos irreparáveis.

As transformações ambientais observadas na ocupação das mais diversas b.h's, no campo e na cidade, apontam para uma crescente pressão social sobre os recursos naturais disponíveis. Os recursos hídricos, por exemplo, tiveram sua demanda elevada em face da diversificação dos seus usos múltiplos e do incremento urbano e agroindustrial — geralmente resultando em impactos ambientais que determinam um descenso nos índices de desenvolvimento social. Como se não bastasse, a compactação dos solos e ablação, desmatamentos, sobretudo da mata ciliar, compactação de várzeas pela pecuária extensiva, anos de secas, com "corte" do fluxo hídrico, são agravados pela intermitência da alimentação do regime fluvial. Esse fato compromete até a perenidade dos leitos dos açudes, desestabilizando a geomorfologia fluvial e a agropecuária nesses trechos. O barramento de cursos d'água rompe a dinâmica dos sistemas em seqüência - mostrando o relacionamento entre vários subsistemas - modificando o input de água na bacia de drenagem, impulsionadora das interações sistêmicas, influenciando no balanço de energia e matéria, comprometendo a geodinâmica e a renovação hídrica. Os fatores da exploração biológica são degradados, comprometendo a teia de relações naturais e o manuseio da biodiversidade. Com efeito, as feições topográficas, os processos morfogenéticos e morfodinâmicos atuantes precisam ser considerados para o uso do solo - agrícola e/ou urbano; isto em uma atenção mais globalizante, no diagnóstico das condições ambientais, colaborando para (re) orientar os assentamentos humanos e as atividades produtivas do ordenamento territorial. O mais grave de tudo isso, e sem respaldo legal, é a privatização das águas, impedindo o acesso da população a esse bem público universal e inalienável. Mesmo porque, não se pode negligenciar que os rios ainda condicionam a vida. 
Quadro 5 - Características e problemas na retificação do canal do riacho Mucambinho (Sobral) e dos rios Granjeiro (Crato) e Maranguapinho (Fortaleza)

\begin{tabular}{|c|l||}
\hline Aspectos do canal & \multicolumn{1}{c|}{ Caracterização } \\
\hline \hline Área ao redor/ocupação & $\begin{array}{l}\text { Estrutura de concreto preservado a pouco deteriorada. Formação de bancos de areias povoados por vegetação. } \\
\text { Lançamento de esgotos. }\end{array}$ \\
\hline \hline Margens & $\begin{array}{l}\text { Ocupação com terrenos e loteamentos, sem erosão aparente. Vegetação herbácea e arbustiva ao fundo. } \\
\text { Pequeno trecho de área permeável. Avenida asfaltada lindeira ao rio. Ocupação urbana densa em trechos } \\
\text { do rio Granjeiro, médio-baixo Mucambinho. Altíssima densidade de ocupação nas várzeas e leito menor } \\
\text { do Maranguapinho, com sérios problemas ambientais deflagrados. Fluxo acentuado de veículos e pessoas. } \\
\text { Proteção do canal com paralelepípedos e mureta. Ajardinamento para paisagismo e permeabilização para } \\
\text { urbanização em Sobral. }\end{array}$ \\
\hline Sedimentos de fundo & Areias e formação de bancos arenosos, blocos de concreto (rejeitos de construção) seixos. \\
\hline \hline Morfologia & Uniforme, obedecendo a um padrão meandrântico. \\
\hline Fluxo & Uniforme, com soleiras e depressões. \\
\hline
\end{tabular}

No contexto da geormorfologia fluvial, destacando os cursos d'água, em seus processos fluviais e formas resultantes dos escoamentos das águas, das principais características que condicionam o regime hidrológico, os rios ainda promovem certo estádio de resiliência dos aspectos bióticos e abióticos. Decerto, o poder de autodepuração dos veios fluviais, bem ou mal, ainda é latente, pela bioprodutividade da vegetação remanescente. Assim a resiliência espaciotemporal ainda se ajunta a outros fatores, como destacou Campos (2002): os efeitos dos raios solares, a precipitação de particulados e a reaeração da água.

Concomitantemente, a poluição e o barramento dos recursos hídricos e as estiolações dos fatores de exploração biológica magnificam os conflitos decorrentes do uso e ocupação da terra. Nesse caso, podem desencadear usos potencialmente competitivos pela água, utilizações complementares, empregos que competem entre si, ditos vinculados e competitivos, e aplicações concomitantemente complementares dependentes e competitivas (CHRISTOFIDIS, 2002). Conflitos entre uso doméstico/público e comercial e agropecuário e industrial/agroindustrial e turismo e lazer e conservação compulsória e especial são corriqueiros.

As alterações ambientais vêm tornando água que ocorre em diferentes estados e formas recurso natural renovável, porém esgotável -, cada vez mais escassa para seus diversos usos. Em razão de usos consuntivos, não consuntivos e conflitos emergentes, Christofidis (2002) assinala que a escassez de água produz uma redução de sua disponibilidade, manifestada tanto na crise atual da saúde quanto no problema de médio prazo da alimentação básica, agravando os índices de qualidade de vida, de hoje e das futuras gerações, no contexto regional. Faz-se mister, urgentemente, evitar litígios (atuais e futuros) para alcance dos usos conjuntivos associados aos partilhados dos recursos hídricos, definindo prioridades e eliminando os riscos de conflitos pelo uso da água. Igualmente, sem adequar o domínio dos usos e usuários da água, suas funções, categorização e escala de necessidades, não haverá melhoria nos índices de mensuração da qualidade de vida da população local e contígua (Quadro 6). Para tanto, esses fatores podem ser mitigados paras as Bacias no Ceará e, servir de base aos Comitês de Bacias constituídos e operantes. 
Quadro 6 - Usos, funções e utilizadores do produto água associados a aspectos de imprescindibilidade, possibilidade de substituição e feitos a jusante em Bacias Hidrográficas

\begin{tabular}{|c|c|c|c|c|c|}
\hline Usos & Funções & Utilizador final/associado & $\begin{array}{l}\text { Imprescindibili- } \\
\text { dade } \\
\text { (I) }\end{array}$ & $\begin{array}{l}\text { Possibilidade de } \\
\text { substituição } \\
\text { (S) }\end{array}$ & $\begin{array}{c}\text { Efeito a } \\
\text { jusante } \\
\text { (J) }\end{array}$ \\
\hline $\begin{array}{c}\text { Bebida e } \\
\text { alimentação }\end{array}$ & $\begin{array}{l}\text { Biológica/ } \\
\text { consumo }\end{array}$ & $\begin{array}{l}\text { Homem/entidade conces-sionária, } \\
\text { empresas de águas minerais, Animal/ } \\
\text { agropecuarísta; Fauna/meio ambiente, } \\
\text { Culti-vos/irrigantes }\end{array}$ & $5,2,5,5$ & $\mathrm{~B}, \mathrm{~B}, \mathrm{~B}, \mathrm{~B}$ & $(-)$ \\
\hline $\begin{array}{l}\text { Higiene/ } \\
\text { Limpeza }\end{array}$ & $\begin{array}{l}\text { Condução/ } \\
\text { diluição/solvente }\end{array}$ & $\begin{array}{l}\text { Homem/entidade } \quad \text { concessioná-ria, } \\
\text { Animal/agropecuarísta, } \\
\text { produtor; Industrial/agro-indústrial }\end{array}$ & $5,5,4$ & $\mathrm{~B}, \mathrm{~B}, \mathrm{C}$ & $(-)$ \\
\hline $\begin{array}{l}\text { Produtor } \\
\text { industrial/ } \\
\text { agroindustrial }\end{array}$ & $\begin{array}{l}\text { Uso da água no } \\
\text { processamento/meio } \\
\text { de produção }\end{array}$ & $\begin{array}{l}\text { Homem/produtor/ } \\
\text { industrial/agroindustrial }\end{array}$ & 3 & $\mathrm{~B} / \mathrm{C}$ & $(-)$ \\
\hline Navegação & $\begin{array}{l}\text { Transporte/ } \\
\text { turismo } \\
\end{array}$ & Homem/empresários do turismo & 1 & B & $(0)(-)$ \\
\hline Refrigeração & $\begin{array}{l}\text { Temperatura/ } \\
\text { conservacão } \\
\end{array}$ & Indústria/agroindústria/comércio & 2 & B & $(-)$ \\
\hline $\begin{array}{l}\text { Sustentação à } \\
\text { vida }\end{array}$ & Consumo (biológica) & Biodiversidade/humano & 5 & B & $(-)$ \\
\hline Lazer e Desporte & Suporte/estética & Homem/clubes/pesque e pague & 3 & B & $(-)$ \\
\hline $\begin{array}{l}\text { Destinação final } \\
\text { (rejeição) }\end{array}$ & Diluição/solvente & Homem/fauna e Flora & 5 & B & $(+)(-)$ \\
\hline
\end{tabular}

Obs: (I) indica a possibilidade existente com a tecnologia atual de alcançar a mesma finalidade com usos alternativos; (S) Reflete a existência de outro produto que possa substituir o "produto água", total ou parcialmente, em algumas de suas funções. Adotou-se indicar se Existe Possibilidade (A), ou Não Existe (B) ou é Parcialmente substituível por algum outro produto (C); (J) Decorrentes da retirada de quantidade e/ou lançamento de resíduos, são indicados como Negativo (-), Positivos (+) ou nulos (0). Fonte: Adaptado de Frade e Alves (1991) in Christofidis (2002).

\section{CONSIDERAÇÕES FINAIS}

A materialização deste trabalho pode subsidiar adequados modos de utilização de ambientes semiáridos, em especial ao disciplinamento de uso e ocupação do solo, tomando uma bacia hidrográfica como unidade tarefa no estudo e planejamento geoambiental, em face da degradação dos recursos naturais, preferencialmente os hídricos e da gestão ambiental com conseqüências nefastas ao estiolamento das águas superficiais.

A investigação da b.h's como unidade natural e do gerenciamento calcada na questão dos recursos hídricos e degradação ambiental, sob o prisma de um contexto amplo de planejamento ambiental, permitirá a execução de trabalhos holísticos na abordagem sobre os recursos hídricos. Concorrendo para destacarmos algumas das vantagens da concepção da bacia hidrográfica como unidade de estudo e intervenção política, eis que:

- Em seu âmbito, é possível subsidiar o desenvolvimento de parcerias e resolução de conflitos para usos dos recursos naturais, como ainda analisar a degradação ambiental tomando-se por base sistemas fluviais;

- Estimula e permite a participação popular, democraticamente, com relação ao poder público, organizações não governamentais (ONG's) e entidades privadas; no que descentraliza os trabalhos de conservação e proteção ambiental, estimulando as integrações comunitária e institucional;

- Comporta-se como uma unidade fisiográfica indissociável possível de ser compartimentada em trabalhos geoambientais integrados;

- Possibilita uma forma racional de organização de banco de dados, além de garantir opções para o uso dos mananciais e de seus recursos naturais; 
- Evidencia o estado de degradação ambiental pela eutrofização, bem como pelo assoreamento dos corpos hídricos; e

Apresenta um arcabouço jurídico-ambiental bem consubstanciado para o combate à degradação ambiental/desertificação, nas Áreas Susceptíveis à Desertificação (ASD’s).

Com a concepção de Bacia Hidrográfica como unidade de manejo geoambiental, auxilia-se também na gestão ambiental, para administração do espaço em tarefa, com maior grau de eficiência para o gestor designado.

Via de regra, as tipologias de uso/ocupação da terra reunidas pelos recursos agrossocioeconômicos, urbano-industrial e usos múltiplos dos recursos hídricos e ambientes hidromórficos, produzem alterações ambientais, nas b.h's. Dentre os principais, registramos a expansão urbana desordenada, com concomitante crescimento desordenado dos núcleos populacionais; concentração de renda no campo e na cidade; emprego de técnicas agrossilvopastoris inadequadas; desmatamentos, queimadas, degradação pedológica; mineração clandestina; carcinicultura; ocupação de Áreas de Preservação Permanente; problemas oriundos do turismo e da agropecuária; poluição dos recursos hídricos e mudanças hidrológicas; aumento expropriador dos Complexos Agroindustriais e privatização das águas; problemas originários da industrialização e redução da biodiversidade etc.

Convém registrar que a fruticultura em alguns perímetros irrigados, como nos baixos cursos do Acaraú e Jaguaribe, mantém relação direta com os mercados globais, no entanto, as salinizações e a sodificação induzidas pelo manejo equivocado da irrigação constituem sério problema que envolve os agropólos. O elevado grau de desperdício dos recursos hídricos e a degradação dos solos na irrigação comprometem a geração de riquezas e melhores nos índices de qualificação sociais no mundo rural.

Uma classificação dos corpos hídricos com diretrizes ambientais para o seu enquadramento, assim como estabelecimento das condições e padrões de lançamento de efluentes, conforme a Resolução CONAMA n 357 (17/03/2005), sendo suas outras diretrizes, também necessárias. Por todos esses motivos, é importante se considerar as mudanças no ambiente fluvial, no espaço e no tempo, desencadeadas pelas interferências humanas e suas resultantes sobre o ambiente; ao menos, que os agentes organizadores do espaço ponham em prática os preceitos da Agenda 21, especialmente o Capítulo 18, que trata da proteção, qualidade e abastecimento dos recursos hídricos, imbricado ao Capítulo 12.2, que considera o semiárido e a desertificação - por este ser um dos maiores problemas ambientais dos sertões como um todo.

Esses capítulos advogam o fato de que é mister: integrar medidas de proteção e conservar mananciais; desenvolver técnicas de partição do público nas decisões; mobilizar recursos hídricos, em especial nas zonas áridas e semiaridas; desenvolver ao abastecimento d'água (dessalinização, reuso e reposição de aqüíferos etc.); e que, no manejo de ecossistemas frágeis em face da luta contra a desertificação e a seca considere-se a degradação da exploração biológica associada às atividades socioeconômicas, incidentes sobre os recursos hídricos, a destacar: a degradação hidrológica superficial, pela perda da cobertura vegetal e a degradação das águas subterrâneas, por alteração das modificações nas condições de recarga. Esta questão ganha maior evidência quando se trata de um dos mais pobres Estados da Federação, tem nas contingências do semiárido, ecozona que perfaz aproximadamente $92 \%$ de seu território, ou pouco mais de $136.000 \mathrm{~km}^{2}$, um forte entrave ao aproveitamento dos recursos naturais, com destaque aos hídricos, associado às políticas não crastinatórias, piegas e pelegas, historicamente arroladas.

Entrementes, segundo Rebouças (2002), a crise de água no País, sobretudo no Nordeste decorre no geral de: um crescimento rápido e desordenado das demandas; degradação da qualidade dos mananciais normalmente utilizados em níveis inimagináveis; pela baixa eficiência dos serviços de saneamento básico; produção de áreas de risco; e agravamento dos efeitos da seca. Isto é conseqüência da urbanização e da industrialização, da história rural de aproveitamento extensivo do 
potencial hídrico do solo; do baixo nível tecnológico/organizacional, no plano primitivo de uso e ocupação do meio rural, ocasionando desmatamentos, contribuído para erosão, empobrecimento das pastagens nativas, redução das reservas de água do solo e conseqüente queda progressiva da sua produtividade natural. Urge, como necessária, a gestão ambiental de bacias de drenagem como unidades de planejamento para minorar ou reverter o estado atual de degradação das paisagens, que reflete, direta ou indiretamente, seus efeitos deletérios na própria qualidade de vida dos povos.

Com esta realidade, concebendo a Bacia Hidrográfica como unidade territorial de planejamento, torna-se urgente reler os paradigmas de desenvolvimento regionais que, atrelados ao nacional e ao internacional, ante a globalização, determinam padrões degradadores e comprometedores de manejo das atividades produtivas, com destaque para as campesinas, em meio a reestruturações produtivas e territoriais seletivas, excludentes e elitistas e para os assentamentos humanos precários nas periferias urbanas.

\section{REFERÊNCIAS BIBLIOGRÁFICAS}

CAMPOS, Nilson. Gestão de Águas: novas visões e paradigmas. In: CAMPOS, N.; STUDART, T. (orgs.). Gestão de Águas: princípios e práticas. Porto Alegre: ABRH, 2002. p.17-24.

CHRISTOFIDIS, Demetrios. Considerações sobre conflitos e uso sustentável em recursos hídricos. In: THEODORO, Suzi (org.). Conflitos e uso sustentável dos recursos naturais. Rio de Janeiro: Garamond, 2002. p. 13-28.

CUNHA, Sandra B. da. Impactos das obras de engenharia sobre o ambiente biofísico da Bacia do rio São João (Rio de Janeiro/Brasil). Rio de Janeiro: Edição do autor, 1995. 415p.

HELLER, L. e CASSEB, M.M. Abastecimento de água. In: Manual de saneamento e proteção ambiental. Belo Horizonte: DESA/GTZ, 1995.

NASCIMENTO, Flávio R. do. Degradação ambiental e desertificação no Nordeste Brasileiro: o contexto da bacia hidrográfica do rio Acaraú - CE. (Tese de doutorado). Niterói: UFF, 2006. 332p.

MINISTÉRIO DO MEIO AMBIENTE (MMA).e Secretária de Recursos Hídricos (SRH). Documento de Introdução. Plano Nacional de Recursos Hídricos. Iniciando um processo de debate nacional. Brasília:MMA/ SRH, 2004. 51p.

OLIVEIRA, Alcinone de e FERREIRA, Elisabeth. Caracterização de Sub-bacias hidrográficas. Lavras: UFLA/FAEPE, 2001. p. 26-38.

REBOUÇAS, Aldo da C. In: REBOUÇAS, A. da C.; BRAGA, B.; e TUNDISI, J. G. (orgs.). Águas doces no Brasil: capital ecológico, uso e conservação. $2^{a}$ edição. São Paulo: Escrituras Editora, 2002. p. 151-199. VIEIRA, Vicente P.P.B. Água Doce no Semi-árido. In: Águas Doces no Brasil: capital ecológico, uso e conservação. $2^{\mathrm{a}}$ edição. São Paulo: Escrituras Editora, 2002. p. 507-530.

Trabalho enviado em agosto de 2011 Trabalho aceito em outubro de 2011 